Article

\title{
First-Principles Calculations of Structural, Mechanical, and Electronic Properties of the B2-Phase NiTi Shape-Memory Alloy Under High Pressure
}

\author{
Fang $\mathrm{Yu}^{1}$ and $\mathrm{Yu} \mathrm{Liu}^{2, *(1)}$ \\ 1 School of Software and Communication Engineering, Xiangnan University, Chenzhou 423000, China; \\ yfang_xnu@163.com \\ 2 State Key Laboratory of Advanced Design and Manufacturing for Vehicle Body, Hunan University, \\ Changsha 410082, China \\ * Correspondence: lyu1006@hnu.edu.cn
}

Received: 26 August 2019; Accepted: 28 September 2019; Published: 30 September 2019

\begin{abstract}
A first-principles calculation program is used for investigating the structural, mechanical, and electronic properties of the cubic NiTi shape-memory alloy (SMA) with the B2 phase under high pressure. Physical parameters including dimensionless ratio, elastic constants, Young's modulus, bulk modulus, shear modulus, ductile-brittle transition, elastic anisotropy, and Poisson's ratio are computed under different pressures. Results indicate that high pressure enhances the ability to resist volume deformation along with the ductility and metallic bonds, but the biggest resistances to elastic and shear deformation occur at $P=35 \mathrm{GPa}$ for the B2-phase NiTi SMA. Meanwhile, the strong anisotropy produced by the high pressure will motivate the cross-slip process of screw dislocations, thereby improving the plasticity of the B2-phase NiTi SMA. Additionally, the results of the density of states (DOS) reveal that the B2-phase NiTi SMA is essentially characterized by the metallicity, and it is hard to induce the structural phase transition for the B2-phase NiTi SMA under high pressure, which provides valuable guidance for designing and applying the NiTi SMA under high pressure.
\end{abstract}

Keywords: NiTi SMA; first-principles calculations; mechanical property; elastic constant; electronic structure; applied pressure

\section{Introduction}

As the representative shape-memory alloys (SMAs), NiTi alloys have been extensively applied in medicine, aerospace, automotive, electronics, machinery, and other industries [1-8], which ascribes to their excellent properties of shape memory effects (SMEs), superelasticity (SE), high-strength, corrosion resistance, and biocompatibility [9-13]. For the studies of NiTi SMAs, plenty of works have been carried out by theory and experiment [14-18]. Haskins and Lawson [19] investigated the temperature-dependent thermodynamic properties of NiTi alloys by density functional theory molecular dynamics (DFT-MD), and then analyzed the finite temperature properties of three phases (ground state monoclinic B33, martensitic B19', and austenitic B2), and the results revealed that the anharmonic effects played a large role in both stabilizing the austenite B2 phase and suppressing the martensitic phase transition. By first-principles calculations, Lee et al. [20] found that the functional stability of the SMA may be related to its structural compatibility between the parent-phase and the martensitic-phase structures, and the ternary NiTi-X alloys tended to have better structural compatibility than the binary equiatomic NiTi alloys, indicating that the functional stability of NiTi SMAs can be effectively improved by alloying additional elements. Liu et al. [21] also utilized the systematic ab-initio simulations to explore the high-pressure behavior of NiTi SMAs at zero temperature 
and found that the known B19 phase was dynamically unstable, and an orthorhombic structure and a face-centered-cubic B32 structure became stable above $\sim 4$ and 29 GPa, respectively. Additionally, in terms of experimental researches, Ataei et al. [22] applied the warm deformation method (an effective thermomechanical processing, TMP) to enhance the shape memory and mechanical properties of the equiatomic NiTi alloy. They found that the property of shape memory recovery can be well improved due to the fully martensitic structure of the $500{ }^{\circ} \mathrm{C}$ processed sample materials, where the shape recovery strain was increased from $1.5 \%$ to $3.6 \%$. Wang et al. [23] investigated the texture-induced anisotropic phase transformation of a rolled NiTi sheet by uniaxial tension and cyclic loading using in situ laboratory X-ray diffraction, and the results revealed that the increasing external applied stress induced the continuous phase transformation with the martensite forming and growing in the highly strained austenitic matrix. However, although many of the above researches have been conducted, they are still unknown for the effects of the applied pressure on the structural, mechanical, and electronic properties of the B2-phase NiTi SMAs due to lack of in-depth researches, thereby preventing the widespread applications of NiTi SMAs under high pressure.

Based on the above unresolved issues, we will utilize the first-principles density-functional theory (DFT) to investigate the related properties of cubic NiTi SMAs with B2 phase under different pressures, mainly including their structural, mechanical, and electronic properties and the relative parameters are also calculated for describing the structural, mechanical, and electronic properties of the B2-phase NiTi SMAs under different pressures. Meanwhile, the results of Zeng et al. [24] concluded that high pressure can quickly suppress the effects of temperature on the volume of thermal expansivity for NiTi SMA. Herein, the temperature effect can be approximately neglected in investigating the impacts of high pressure on the properties of NiTi SMA. Additionally, Sandoval et al. [25] recently found that the transformation temperature of the B2-phase NiTi SMA dropped below $5 \mathrm{~K}$ at very high twin densities, thus, the following DFT calculations can be effectively carried out under the ground state. The main structures in the following text are methodically arranged as follows: Section 2 introduces the detailed methodology of this work and crystal structure model for calculating related properties of the B2-phase NiTi SMAs; Section 3 gives the research results, and then discusses the influences of applied pressure on the related properties of the B2-phase NiTi SMAs in detail; Section 4 summarizes the research conclusions in this work.

\section{Methodology}

The program of Cambridge Serial Total Energy Package [26-28] was chosen to carry out the DFT total energy calculations, and the results of these calculations helped to get the various ground state energies and electronic structures of the cubic NiTi SMAs under different pressures. We chose the generalized gradient approximation (GGA) of the Perdew-Burke-Eruzerhof [29] as the exchange-correlation function. The ion-electron interactions were addressed by the ultrasoft pseudopotentials [30], and the valence electrons of the $\mathrm{Ni}$ and Ti atoms were described as $\mathrm{Ni}\left(4 \mathrm{~s}^{2} 3 \mathrm{p}^{6} 3 \mathrm{~d}^{8}\right)$ and $\operatorname{Ti}\left(4 s^{2} 3 p^{6} 3 d^{2}\right)$, respectively. Herein, the spin-orbit coupling calculation was executed due to the magnetic Ni atoms, and the magnetic moments of the Ni and Ti atoms were $0.64 \mu_{\mathrm{B}}$ and $0.08 \mu_{\mathrm{B}}$, respectively. The total magnetic moment of the unit cell was $0.66 \mu_{\mathrm{B}}$ at $P=0 \mathrm{GPa}$, and the magnetic moments varied under different pressures when the applied pressure was not $0 \mathrm{GPa}$. We carried out a rigorous convergence test of basic parameters before the DFT calculations, and the cutoff energy of the plane-wave basis was set as $400 \mathrm{eV}$, as well as $13 \times 13 \times 13 k$-point grid for the Brillouin zone sampling [31], which were accurate enough to calculate the energies of the NiTi SMAs under different pressures. Meanwhile, we selected the Broyden-Fletcher-Goldfarb-Shanno (BFGS) algorithm [32] as the structural optimization algorithm for all DFT calculations in this work, and the range of applied pressures changed from -10 to $50 \mathrm{GPa}$. In self-consistent calculations, the energy parameter of the convergence criterion was set to $1.0 \times 10^{-6} \mathrm{eV} /$ atom, and the Hellmann-Feynman atomic force was less than $0.01 \mathrm{eV} / \AA$. Figure 1 depicts the cubic structure model of the B2-phase NiTi SMA with the $P m-3 m$ space group. 


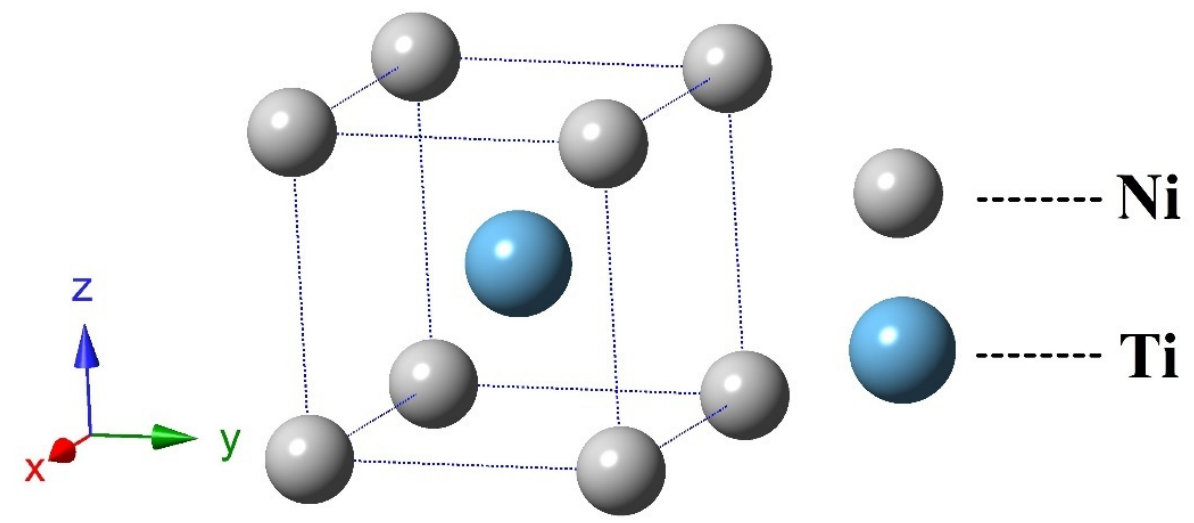

Figure 1. Cubic structure model of B2-phase NiTi shape-memory alloy (SMA).

\section{Results and Discussions}

\subsection{Structure Properties and Stability}

Firstly, before investigating the structural, mechanical, and electronic properties of the B2-phase NiTi SMA, we confirmed the most stable crystal structure of the B2-phase NiTi SMA by the energy-volume $(E-V)$ curve, as depicted in Figure 2, where the $E-V$ curve was obtained by precisely fitting the calculated $E-V$ data, which was decided by the fitting method of the Birch-Murnaghan equation of state [33]. For ease of calculations, the interval of volume $V$ changed only from $0.7 V_{0}$ to $1.2 V_{0}$. Therefore, we fully optimized the unit cell of the B2-phase NiTi SMA within the above volume interval, aiming to determine the structural parameters in a stable state. Figure 2 demonstrates the calculated and fitting results, and Table 1 lists the calculated $E-V$ data of the B2-phase NiTi SMA under the ground state $(P=0$ and $T=0)$, and it can be found that the total energy was at a minimum $\left(E_{t}=-14.025 \mathrm{eV}\right)$ at $V=V_{0}\left(V_{0}=27.130 \mathrm{~A}^{3}\right)$, and the lattice constant was accordingly $a_{0}=3.005 \mathrm{~A}$, which denotes the equilibrium structural parameters of the B2-phase NiTi SMA in a stable state. Moreover, $a_{0}$ and $V_{0}$ indicated the equilibrium lattice constant and primitive cell volume under the ground state, respectively. The calculated results fit well with the other theoretical [14-16,19,34-38] and experimental results [34,39], and these are compared in Table 2.

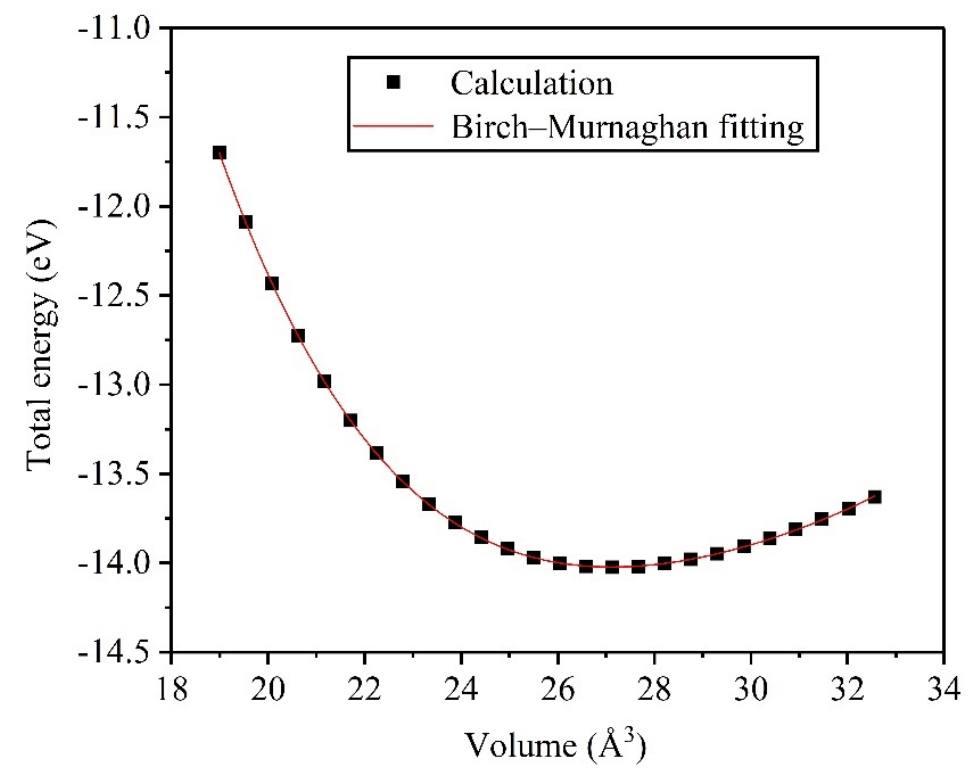

Figure 2. The Birch-Murnaghan fitting curve of the $E-V$ data for the NiTi SMA. 
Table 1. The calculated $E-V$ data of B2-phase NiTi SMA under the ground state.

\begin{tabular}{lcccccccccc}
\hline$V\left(\AA^{3}\right)$ & 18.990 & 19.540 & 20.080 & 20.620 & 21.160 & 21.710 & 22.250 & 22.790 & 23.330 & 23.880 \\
$E(\mathrm{eV})$ & -11.696 & -12.090 & -12.433 & -12.729 & -12.983 & -13.201 & -13.386 & -13.541 & -13.669 & -13.774 \\
$V\left(\AA^{3}\right)$ & 24.420 & 24.960 & 25.500 & 26.050 & 26.590 & 27.130 & 27.670 & 28.220 & 28.760 & 29.300 \\
$E(\mathrm{eV})$ & -13.857 & -13.922 & -13.969 & -14.001 & -14.019 & -14.025 & -14.019 & -14.004 & -13.980 & -13.948 \\
\hline
\end{tabular}

Table 2. Comparisons of the equilibrium lattice constant of this work to the other theoretical and experimental results for the B2-phase NiTi SMA.

\begin{tabular}{cccc}
\hline B2-phase NiTi & This Work & Theoretical Results & Experimental Results \\
\hline \multirow{2}{*}{ Lattice constant $a(\AA)$} & \multirow{2}{*}{3.005} & $2.997[14], 3.021[15], 3.010[16]$, & \\
& & $3.005[19], 2.940[34], 3.019[35]$, & $3.010[34], 3.013[39]$ \\
\hline
\end{tabular}

For studying the influences of applied pressure on the basic structural parameters of the NiTi SMA, we calculated the corresponding cell volumes $V$ and the lattice constants $a$ under different pressures by fully optimizing the crystal structure of the NiTi SMA, and then the ratios of $V / V_{0}$ and $a / a_{0}$ were obtained for describing the changes of the cell volume and lattice constant under different pressures, as shown in Figure 3. The high pressure decreased the ratios of $V / V_{0}$ and $a / a_{0}$, leading to the rapid decrease of the cell volume and lattice constant. Namely, high pressure shortened the spacing between the adjacent atoms, and the electron interactions between the adjacent atoms became stronger under high pressure.

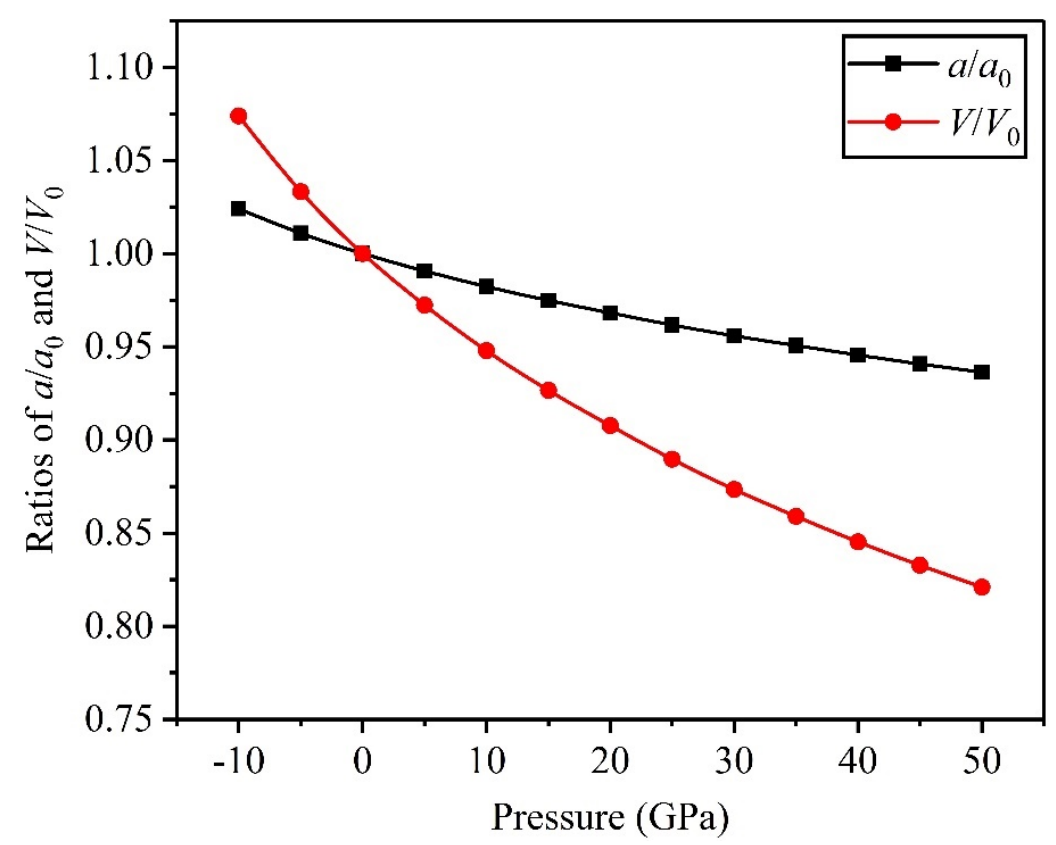

Figure 3. Variation curves of the ratios $V / V_{0}$ and $a / a_{0}$ under different pressures for the NiTi SMA.

By quadratic polynomial fitting in Figure 3, the calculated results of the ratios $V / V_{0}$ and $a / a_{0}$ as a function of applied pressure are accurately fitted as follows:

$$
\begin{aligned}
& V / V_{0}=1.004-5.800 \times 10^{-3} P+4.424 \times 10^{-5} P^{2} \\
& a / a_{0}=1.001-1.940 \times 10^{-3} P+1.342 \times 10^{-5} P^{2}
\end{aligned}
$$

For anisotropic materials of cubic crystals, the elastic constants $C_{11}, C_{12}$, and $C_{44}$ are defined as the three key parameters to indicate the ability to resist external forces, and describe the structural 
stability of the materials. In the light of the stability criterion of cubic crystals [40,41], the following inequations must be true in any case for structurally stable materials:

$$
\left(C_{11}-C_{12}\right)>0, C_{11}>0, C_{44}>0,\left(C_{11}+2 C_{12}\right)>0
$$

To compare the calculated results of other parameters, Table 3 lists the calculated values of elastic constants, bulk modulus $B$, Young's modulus $E$, shear modulus $G$, and Poisson's ratio $\sigma$, and they agree well with these theoretical $[19,34,35,42,43]$ and experimental results [44]. Notably, the magnetization plays some important role in determining the final results of Table 3 in the process of the spin-polarization calculation.

Table 3. Comparisons of the calculated results to the theoretical and experimental results for the B2-phase NiTi SMA.

\begin{tabular}{llll}
\hline \multicolumn{1}{c}{ B2-Phase NiTi } & \multicolumn{1}{c}{ This Work } & \multicolumn{1}{c}{ Theoretical Results } & \multicolumn{1}{c}{ Experiments } \\
\hline$C_{11}(\mathrm{GPa})$ & 188 & $184[19], 218[34], 183[35], 204[42]$ & $162[44]$ \\
$C_{12}(\mathrm{GPa})$ & 131 & $156[19], 178[34], 146[35], 134[42]$ & $132[44]$ \\
$C_{44}(\mathrm{GPa})$ & 51 & $48[19], 71[34], 46[35], 53[42]$ & $36[44]$ \\
$B(\mathrm{GPa})$ & 150 & $165[19], 191[34], 159[35], 157[42], 158[43]$ & \\
$E(\mathrm{GPa})$ & 112 & $83[19], 120[34], 90[35], 123[42]$ & \\
$G(\mathrm{GPa})$ & 41 & $29[19], 43[34], 32[35], 45[42]$ & \\
$\sigma$ & 0.38 & $0.42[19], 0.40[34], 0.41[35], 0.37[42]$ & \\
\hline
\end{tabular}

In Figure 4, we depicted the variation curves of elastic constants $C_{11}, C_{12}$, and $C_{44}$ as a function of the applied pressure for the NiTi SMA, and it can be seen that with increasing the applied pressure, all of the three elastic constants $C_{11}, C_{12}$, and $C_{44}$ increased by varying degrees, and they were all positive in spite of the arbitrary high pressure. Additionally, the difference values of $C_{11}-C_{12}$ between $C_{11}$ and $C_{12}$ were always positive as well under any pressures. According to the stability criterion of Equation (3), the crystal structure of the NiTi SMA will remain stable all the time in the pressure range of $50 \mathrm{GPa}$, namely, the high pressure is hard to produce the structural phase transition for the NiTi SMA, which fits well with the results of Bakhtiari et al. [45].

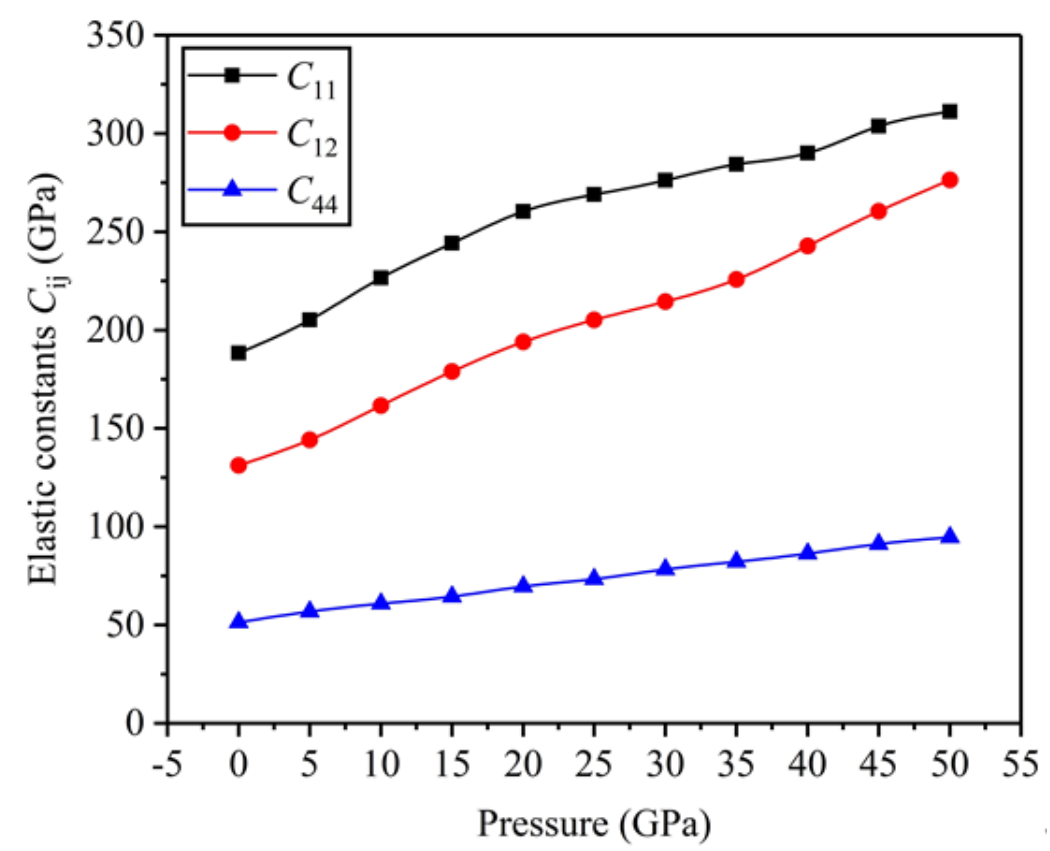

Figure 4. Variation curves of the elastic constants $C_{i j}$ under different pressures for the NiTi SMA. 


\subsection{Mechanical Properties}

The material modulus, like bulk modulus $B$, Young's modulus $E$, and shear modulus $G$, plays a key role in investigating their mechanical properties, and the magnitude of this modulus directly determines the ability to resist material deformations, such as the resistances to bulk deformation, elastic deformation, and shear deformation. Moreover, the larger modulus values induced a stronger ability to resist material deformations [46,47]. Based on Equations (4)-(6) [48], the values of the material modulus are calculated as a function of the elastic constants in Table 3 ,

$$
\begin{gathered}
B=\frac{1}{3}\left(C_{11}+2 C_{12}\right) \\
G=\frac{1}{2}\left(G_{V}+G_{R}\right) \\
E=\frac{9 B G}{3 B+G}
\end{gathered}
$$

here, $G_{V}=\left(C_{11}-C_{12}+3 C_{44}\right) / 5$ and $G_{R}=5\left(C_{11}-C_{12}\right) C_{44} /\left[4 C_{44}+3\left(C_{11}-C_{12}\right)\right]$, and the variables $G_{V}$ and $G_{R}$ indicate the Voigt and Reuss shear modulus, respectively.

By using the Equations (4)-(6), we calculated the bulk modulus $B$, Young's modulus $E$, and shear modulus $G$ under different pressures, and the variation curves of them as a function of the applied pressure are plotted in Figure 5. It can be found that as the applied pressure increased, the value of the bulk modulus $B$ increased as well, thereby suggesting that the high pressure enhanced the ability to resist volume deformation for the NiTi SMA, and the maximum value can reach $288.01 \mathrm{GPa}$ at $P=50 \mathrm{GPa}$. For the calculated results of Young's modulus $E$ and shear modulus $G$, however, it can be seen that they all increased and then decreased in the pressure range of $0 \sim 50 \mathrm{GPa}$, thus, these were the maximum values for the modulus $E$ and $G$ in the process of pressure change, and the maximum values were $151.94 \mathrm{GPa}$ for Young's modulus $E$, as well as $54.39 \mathrm{GPa}$ for shear modulus $G$ at $P=35 \mathrm{GPa}$, respectively, which means that the pressure values at this point can produce the strongest ability to resist elastic and shear deformations for the NiTi SMA.

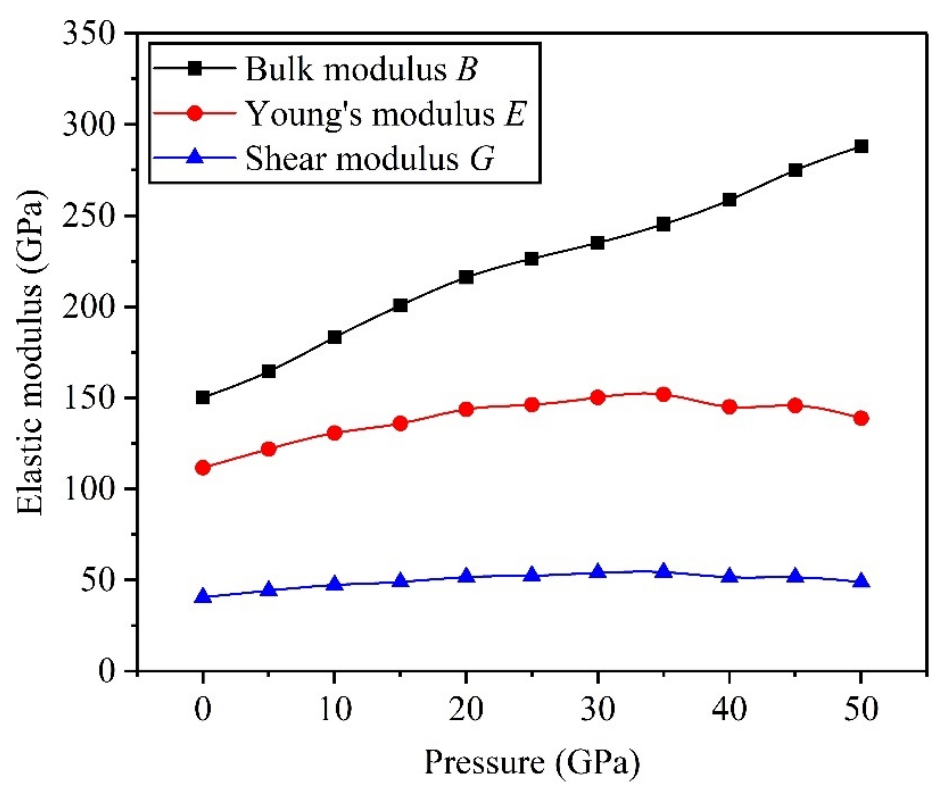

Figure 5. Variation curves of bulk modulus B, Young's modulus $E$, and shear modulus $G$ under different pressures for the NiTi SMA.

Ductile-brittle transition plays a vital role in the structural phase transition of materials. According to the work of Pugh [46], the ductile/brittle properties of polycrystalline materials can be decided 
by the value of the modulus ratio $B / G$, and 1.75 was considered as the critical value to determine the ductile/brittle properties of the materials. For the ductile materials, the value of the ratio $B / G$ was $B / G>1.75$, and for the brittle materials, one of the ratios $B / G$ was $B / G<1.75$. Additionally, the larger $B / G$ ratio produced the stronger ductility, and the smaller $B / G$ ratio induced the stronger brittleness. Hill [49] also put forward that the ductile-brittle transition of the intermetallic compounds was determined by the value of modulus ratio $B / G$. In this work, Figure 6 demonstrates the variation curve of the modulus ratio $B / G$ as a function of the applied pressure, and it can be found that the value of the ratio $B / G$ was about $3.702(>1.75)$ at $P=0 \mathrm{GPa}$, and their values increased gradually with increasing applied pressure. As a result, the NiTi SMA presented good ductility in nature, and the ductility became stronger under high pressure.

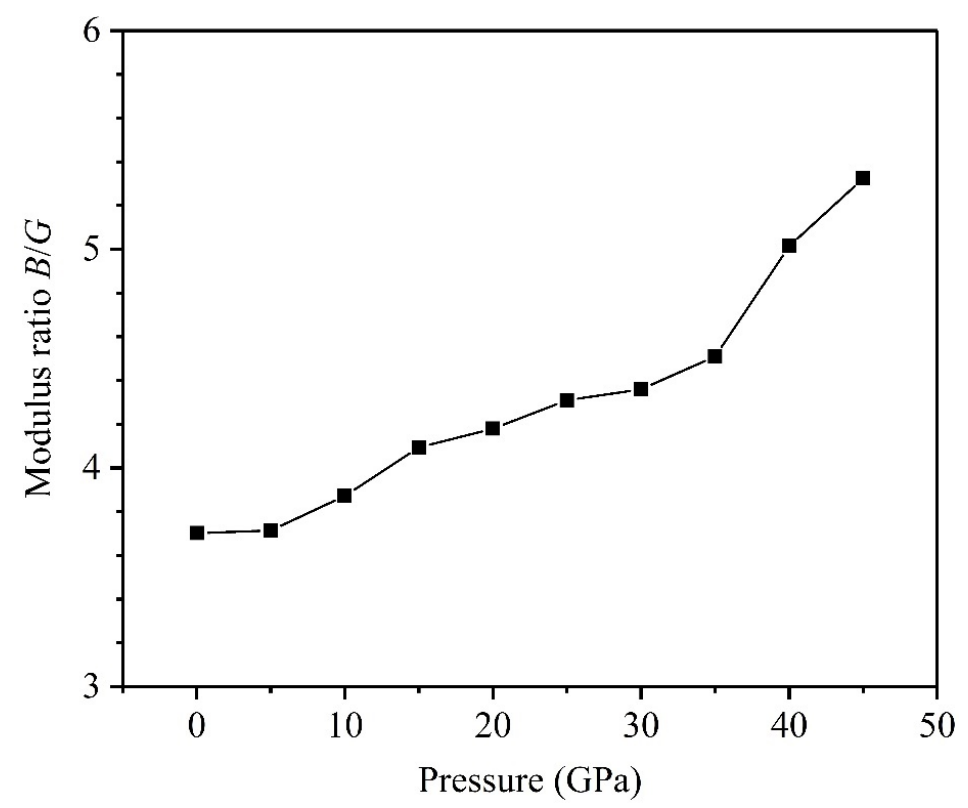

Figure 6. Variation curve of modulus ratio $B / G$ under different pressures for the NiTi SMA.

\subsection{Elastic Anisotropy}

The elastic anisotropy was a significant physical quantity for revealing the essential properties of anisotropic materials, as well as their mechanical properties. The anisotropy factor $A$ was defined as the vital physical parameter for describing the material anisotropy, and the magnitude of the anisotropy factor $A$ was used to indicate the degree of material anisotropy and $A=1$ denoted the isotropic material. Otherwise, it was the anisotropic material. Moreover, if the value of the anisotropy factor $A$ were larger or smaller than 1 , the material anisotropy would be stronger [50,51]. Meanwhile, Yoo [52] investigated the dependencies of the mechanical properties on the anisotropy factor $A$ by establishing the cross-slip-pinning model, and the results indicated that the bigger factor $A$ could promote the screw dislocation motion with the help of the larger driving force, and then lead to the cross-slip-pinning process. In this work, we utilized Equations (7) and (8) to calculate the anisotropy factors $A_{(100)[001]}$ and $A_{(110)[001]}$, which depends on the three elastic constants of the cubic crystals [53,54]:

$$
\begin{gathered}
A_{(100)[001]}=\frac{2 C_{44}}{C_{11}-C_{12}} \\
A_{(110)[001]}=\frac{C_{44}\left(C^{\prime}+2 C_{12}+C_{11}\right)}{C_{11} C^{\prime}-C_{12}{ }^{2}}
\end{gathered}
$$

here, $C^{\prime}=C_{44}+\left(C_{11}+C_{12}\right) / 2, A_{(100)[001]}$ denotes the anisotropy factor in the (100)[001] direction, and $A_{(110)[001]}$ signifies the one in the (110)[001] direction, respectively. With the help of Equations 
(7) and (8), we calculated the values of the two anisotropy factors $A_{(100)[001]}$ and $A_{(110)[001]}$ under different pressures, as depicted in Figure 7. It can be found in Figure 7 that the essential properties of NiTi SMA present the anisotropy due to the anisotropy factors unequal to 1, which are decided by $A_{(100)[001]}=1.798$ and $A_{(110)[001]}=1.508$ under $P=0 \mathrm{GPa}$. With increasing applied pressure, both $A_{(100)[001]}$ and $A_{(110)[001]}$ increased and $A_{(100)[001]}$ increased faster than $A_{(110)[001]}$ under high pressure, which suggests that high pressure induced the strong anisotropy for the NiTi SMA, and the anisotropy in the (100)[001] direction was stronger than the one in the (110)[001] direction. Additionally, the strong anisotropy produced by the high pressure will motivate the cross-slip process of the screw dislocations, thereby improving the plasticity of NiTi SMA.

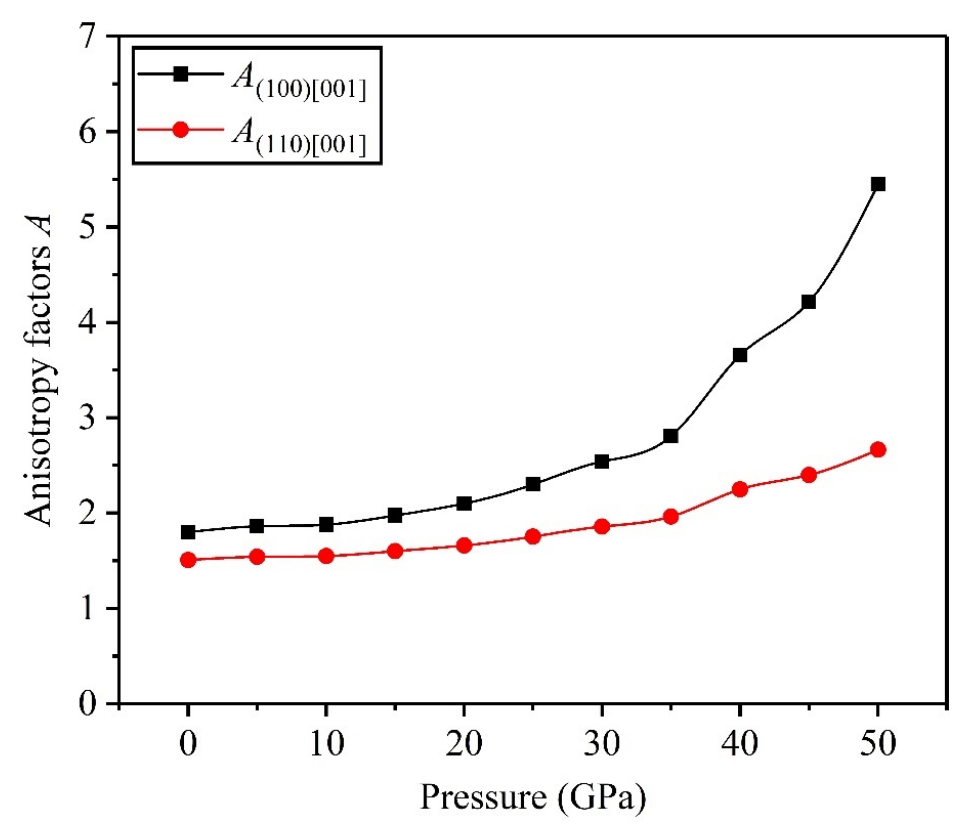

Figure 7. Variation curves of anisotropy factors under different pressures for the NiTi SMA.

From studying the effects of the applied pressure on the plastic properties of NiTi SMA, we calculated the values of Poisson's ratio $\sigma$ as a function of the applied pressure, as shown in Figure 8. The magnitude of Poisson's ratio $\sigma$ changed from -1 to 0.5 in general, and the bigger Poisson's ratio $\sigma$ induced better plasticity. Fu et al. [54] pointed out that Poisson's ratio $\sigma$ was mainly decided by the type of interatomic bonding when only considering the critical factors of the atomic scale. Reed and Clark [55] found that Poisson's ratios $\sigma_{\max }=0.5$ and $\sigma_{\min }=0.25$ were considered as the maximum and minimum in the process of studying central force solids, respectively. By Equations (9) and $(10)[54,56]$, we calculated the values of Poisson's ratios $\sigma_{[001]}$ and $\sigma_{[111]}$ in the [001] and [111] directions under different pressures (see Figure 8). It can be seen in Figure 8 that the values of $\sigma_{[001]}$ and $\sigma_{[111]}$ were 0.411 and 0.347 under $P=0 \mathrm{GPa}$, respectively, suggesting that the interatomic bonding of the NiTi SMA was generally bonded by the central force in the [001] and [111] directions. With increasing the applied pressure, the values of $\sigma_{[001]}$ dramatically increased, but the ones of $\sigma_{[111]}$ had little change compared with $\sigma_{[001]}$, but there was a maximum value $\left(\sigma_{[111]_{\max }}=0.355\right)$ at $P=15 \mathrm{GPa}$, which implied that the central force of the NiTi SMA was enhanced in the [001] direction, along with the improved plasticity, but the plasticity in the [111] direction hardly had great changes.

$$
\begin{gathered}
\sigma_{[001]}=\frac{C_{12}}{C_{11}+C_{12}} \\
\sigma_{[111]}=\frac{C_{11}+2 C_{12}-2 C_{44}}{2\left(C_{11}+2 C_{12}+C_{44}\right)}
\end{gathered}
$$




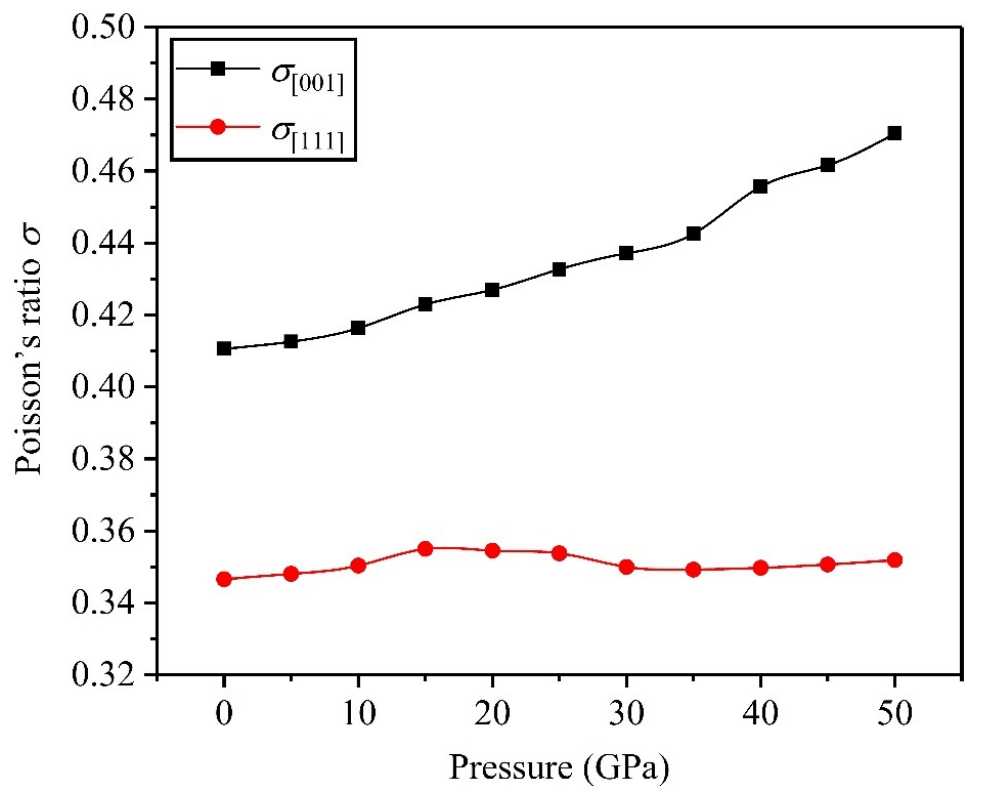

Figure 8. Variation curves of Poisson's ratios under different pressures for the NiTi SMA.

To further investigate the mechanical properties of the NiTi SMA, we calculated the other modulus to evaluate the non-deformability and material strength. $G_{(100)[010]}$ and $G_{(110)[1 \overline{1} 0]}$ are defined as the two shear moduli for measuring the non-deformability in the (100) [010] and (110) [1 $\overline{1} 0]$ directions, respectively, and they can be calculated by $G_{(100)[010]}=C_{44}$ and $G_{(110)[1 \overline{1} 0]}=\left(C_{11}-C_{12}\right) / 2$. Meanwhile, $E_{\langle 100\rangle}$ is also defined as Young's modulus in the $\langle 100\rangle$ directions, which is calculated by $E_{\langle 100\rangle}=\left(C_{11}-C_{12}\right)\left[1+C_{12} /\left(C_{11}+C_{12}\right)\right][51,57]$. Based on these moduli, we plotted Figure 9 for demonstrating the variation curves of the three moduli as a function of applied pressure, and the results revealed that the value of $G_{(100)[010]}$ was always bigger than the one of $G_{(110)[1 \overline{1} 0]}$ within the pressure range of the study, suggesting that the resistance to shear deformation in the (100) [010] direction was stronger than the one in the (110) [110] direction. Furthermore, it can be seen that the values of $G_{(100)[010]}$ increased linearly with an increment of applied pressure, which means that the resistance to shear deformation in the (100) [010] direction was effectively improved under high pressure. Nevertheless, the values of $G_{(110)[1 \overline{1} 0]}$ first increased and then decreased with an increment of applied pressure, and there exists a maximum value $\left(G_{(110)[1 \overline{1} 0]_{\max }}=33.17 \mathrm{GPa}\right)$ at $P=20 \mathrm{GPa}$, thereby indicating that the resistance to shear deformation in the $(110)[1 \overline{1} 0]$ direction was the strongest at $P=20 \mathrm{GPa}$. The calculated result of Young's modulus $E_{\langle 100\rangle}$ shows that $E_{\langle 100\rangle}$ first increased and then decreased with an increment of applied pressure, and there also exists a maximum value $\left(E_{\langle 100\rangle_{\max }}=94.68 \mathrm{GPa}\right)$ at $P=20 \mathrm{GPa}$, thereby suggesting that the resistance to elastic deformation in the $\langle 100\rangle$ directions was also the strongest at $P=20 \mathrm{GPa}$. The Cauchy pressure was defined as the difference value $C_{12}-C_{44}$ between the elastic constants $C_{12}$ and $C_{44}$, which helped to grasp the characteristics of the atomic bonding of the materials, and well revealed the nature of bonding from the atomic scale [58]. In the light of the works of Johnson [59] and Fu et al. [51], the positive Cauchy pressure indicated the metallic properties between atomic bonding, and the homogeneous electron gases without regionality and directionality were distributed around the spherical atoms, but the negative Cauchy pressure exhibited the characteristic of directional bonding, and the directional characteristic increased with an increment of Cauchy pressure. In Figure 9, the calculated Cauchy pressures $C_{12}-C_{44}$ were always positive values under any pressures, and they increased basically with an increment of applied pressure, which reveals that the atomic bonding of the NiTi SMA was characterized by the metallic bond, and their metallic bonds were enhanced under high pressure. 


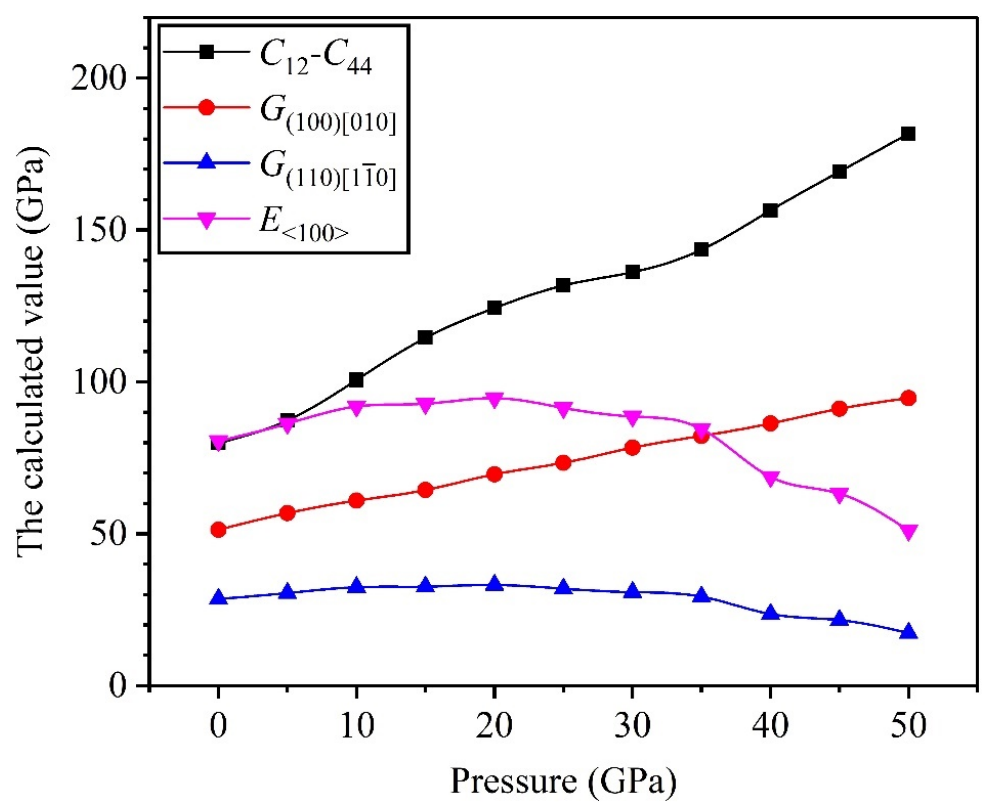

Figure 9. Variation curves of the calculated modulus under different pressures for the NiTi SMA.

\subsection{Electronic Properties}

In this work, we calculated the electronic structures of the NiTi SMA to reveal the bonding mechanisms and stability changes under different pressures. As shown in Figure 10, the partial DOS (PDOS) and total DOS (TDOS) of the NiTi SMA are clearly plotted at $P=0 \mathrm{GPa}$, and the Fermi level $\left(E_{\mathrm{F}}=0 \mathrm{eV}\right)$ is labeled by the red dash line. It can be found from Figure 10 that the value of TDOS at $E_{\mathrm{F}}$ was not zero, thereby suggesting that the NiTi SMA was essentially characterized by the metallicity, and the result fits well with the one in Figure 9. Moreover, the results of PDOS indicate that Ni-3d and Ti-3d states are the two key factors for contributing to TDOS at the Fermi level $E_{\mathrm{F}}$, and the other states hardly have any contributions to TDOS.

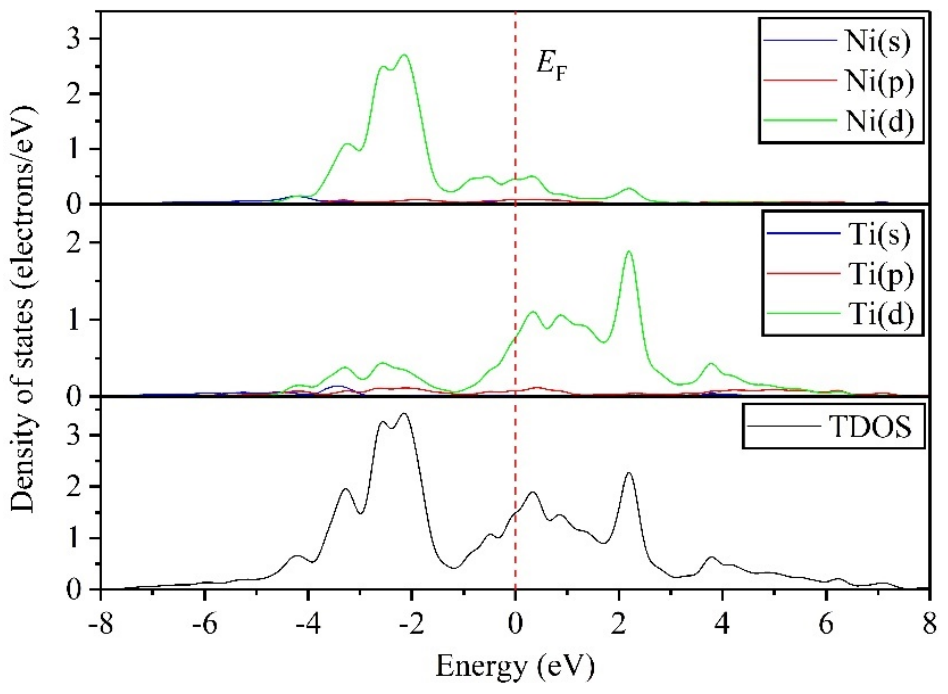

Figure 10. Partial density of states (PDOS) and total DOS (TDOS) for the NiTi SMA under $P=0$ GPa.

Meanwhile, the impacts of applied pressure on TDOS of the NiTi SMA were also studied for revealing the variation of the band gap between the valence band and conduction band, as depicted in Figure 11. As the applied pressure increased, the energies of the valence band increased slightly, and the ones of the conduction band remain unchanged under any pressures, which led to the slight 
diminution of the band gap, thus, the driving force of the electron transition from the valence band to the conduction band had a little increase under high pressure, namely, the binding force was still strong under high pressure, and it was hard to induce the structural phase transition for the NiTi SMA under high pressure.

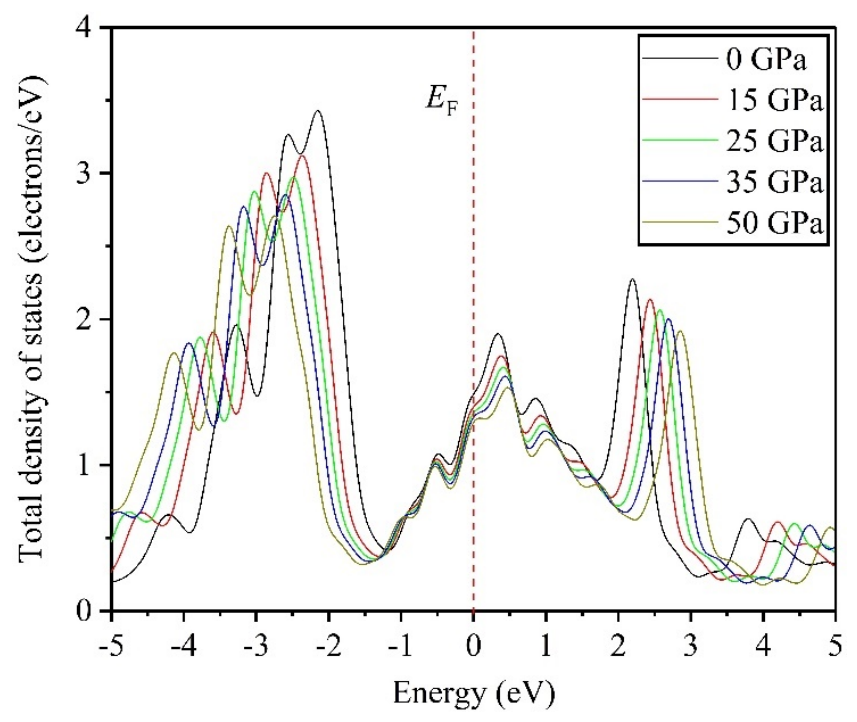

Figure 11. TDOS for the NiTi SMA under different pressures.

Additionally, we also drew the schematic of the isosurface contours of charge density under different pressures, as shown in Figure 12, which clearly depicts the electron interactions between Ni and $\mathrm{Ti}$ atoms. With increasing applied pressure, the local charge densities of both $\mathrm{Ni}$ and $\mathrm{Ti}$ atoms increased slightly, and then the electron interactions between them were also slightly enhanced, thereby implying that the local chemical bonding composed of electrons and ions remains almost unchanged under high pressure. Therefore, the high pressure had a little effect on the structural stability of the NiTi SMA, and the structural phase transition was hard to occur for the NiTi SMA.

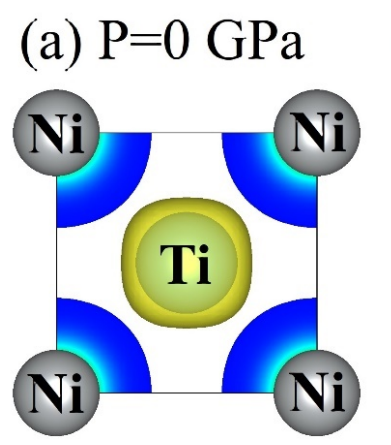

(b) $\mathrm{P}=25 \mathrm{GPa}$
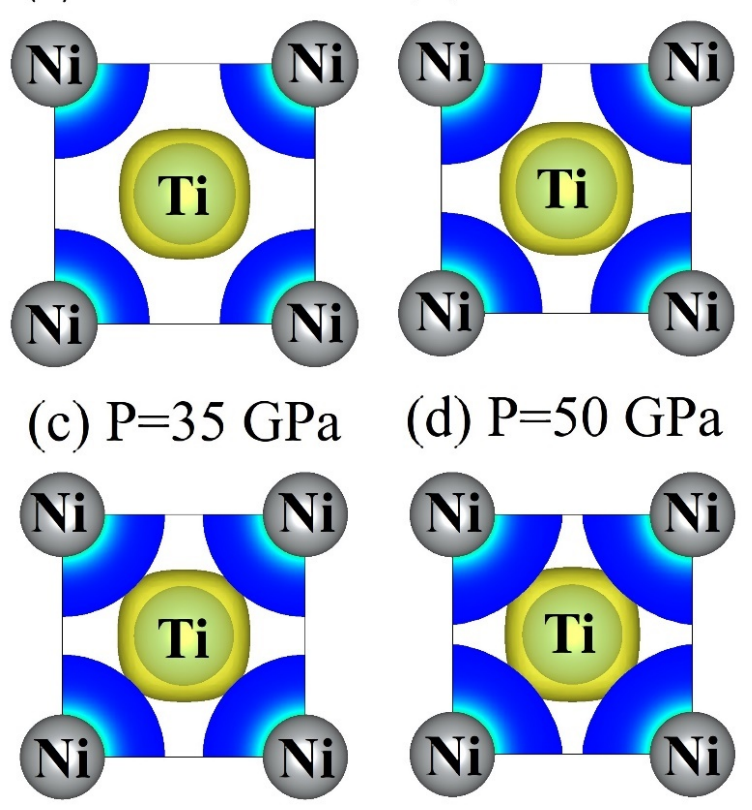

Figure 12. Schematic of isosurface contours of charge density for the NiTi SMA under different pressures; the isosurface levels are set as $0.045 r_{0}^{-3}$ ( $r_{0}$ : Bohr radius). 


\section{Conclusions}

In conclusion, this work aims to investigate the structural, mechanical, and electronic properties of the B2-phase NiTi SMA under high pressure by DFT calculations, and the relevant conclusions are summarized as follows:

(1) High pressure enhances the ability to resist volume deformation, but the strongest resistances to elastic and shear deformations occur at $P=35 \mathrm{GPa}$ for the B2-phase NiTi SMA.

(2) Pugh's ratio $B / G$ reveals that the B2-phase NiTi SMA presents good ductility in nature, and high pressure can improve the ductility of the B2 phase.

(3) The strong anisotropy produced by high pressure will motivate the cross-slip process of screw dislocations, thereby improving the plasticity of the B2-phase NiTi SMA.

(4) The resistance to shear deformation in the (100) [010] direction is stronger than the one in the (110) $[1 \overline{1} 0]$ direction, and the resistance to shear deformation in the (110) [11 $\overline{1} 0]$ direction and elastic deformation in the $\langle 100\rangle$ directions are the strongest at $P=20 \mathrm{GPa}$. Results of Cauchy pressure indicate that the atomic bonding of the B2-phase NiTi SMA is characterized by the metallic bond, and high pressure enhances the metallic bonds.

(5) Results of DOS reveal that the B2-phase NiTi SMA is essentially characterized by the metallicity, but it is hard to induce the structural phase transition for the B2-phase NiTi SMA under high pressure.

Author Contributions: Conceptualization, F.Y. and Y.L.; methodology, F.Y. and Y.L.; software, F.Y.; validation, F.Y. and Y.L.; formal analysis, F.Y. and Y.L.; investigation, F.Y. and Y.L.; resources, F.Y.; data curation, F.Y. and Y.L.; writing-original draft preparation, F.Y. and Y.L.; writing—review and editing, F.Y. and Y.L.; visualization, F.Y.; supervision, F.Y. and Y.L.; project administration, F.Y. and Y.L.; funding acquisition, F.Y.

Funding: This research was funded by the Cooperative Education Program of Ministry of Education of China (No. 201801238024), Innovation and Entrepreneurship Education Center Project of Hunan Provincial Education Department ([2018]380-74), and Chenzhou Municipal Science and Technology Bureau of Research on Real-Time Monitoring System of Intelligent Trash Can ([2018]102).

Acknowledgments: We deeply appreciate the computing resources offered by the National Supercomputing Center in Shenzhen, China.

Conflicts of Interest: The authors declare no conflict of interest.

\section{References}

1. Duerig, T.; Pelton, A.; Stöckel, D. An overview of nitinol medical applications. Mater. Sci. Eng. A 1999, 273-275, 149-160. [CrossRef]

2. Michiardi, A.; Aparicio, C.; Planell, J.A.; Gil, F.J. Electrochemical behaviour of oxidized NiTi shape memory alloys for biomedical applications. Surf. Coat. Technol. 2007, 201, 6484-6488. [CrossRef]

3. Morgan, N.B. Medical shape memory alloy applications-The market and its products. Mater. Sci. Eng. A 2004, 378, 16-23. [CrossRef]

4. Chau, E.T.F.; Friend, C.M.; Allen, D.M.; Hora, J.; Webster, J.R. A technical and economic appraisal of shape memory alloys for aerospace applications. Mater. Sci. Eng. A 2006, 438-440, 589-592. [CrossRef]

5. Jani, J.M.; Leary, M.; Subic, A.; Gibson, M.A. A review of shape memory alloy research, applications and opportunities. Mater. Des. 2014, 56, 1078-1113. [CrossRef]

6. Pozzi, M.; Airoldi, G. The electrical transport properties of shape memory alloys. Mater. Sci. Eng. A 1999, 273-275, 300-304. [CrossRef]

7. Schetky, L.M. Shape memory alloy applications in space systems. Mater. Des. 1991, 12, 29-32. [CrossRef]

8. Elahinia, M.H.; Hashemi, M.; Tabesh, M.; Bhaduri, S.B. Manufacturing and processing of NiTi implants: A review. Prog. Mater. Sci. 2012, 57, 911-946. [CrossRef]

9. Otsuka, K.; Ren, X. Physical metallurgy of Ti-Ni-based shape memory alloys. Prog. Mater. Sci. 2005, 50, 511-678. [CrossRef]

10. Plietsch, R.; Ehrlich, K. Strength differential effect in pseudoelastic NiTi shape memory alloys. Acta Mater. 1997, 45, 2417-2424. [CrossRef]

11. Li, D.S.; Zhang, Y.P.; Eggeler, G.; Zhang, X.P. High porosity and high-strength porous NiTi shape memory alloys with controllable pore characteristics. J. Alloys Compd. 2009, 470, L1-L5. [CrossRef] 
12. Starosvetsky, D.; Gotman, I. Corrosion behavior of titanium nitride coated Ni-Ti shape memory surgical alloy. Biomaterials 2001, 22, 1853-1859. [CrossRef]

13. Es-Souni, M.; Es-Souni, M.; Fischer-Brandies, H. On the properties of two binary NiTi shape memory alloys. Effects of surface finish on the corrosion behaviour and in vitro biocompatibility. Biomaterials 2002, 23, 2887-2894. [CrossRef]

14. Li, Y.C.; Wang, F.H.; Shang, J.X. Ab initio study of oxygen adsorption on the NiTi (110) surface and the surface phase diagram. Corros. Sci. 2016, 106, 137-146. [CrossRef]

15. Chowdhury, P.; Patriarca, L.; Ren, G.W.; Sehitoglu, H. Molecular Dynamics Modeling of NiTi Superelasticity in Presence of Nanoprecipitates. Int. J. Plast. 2016, 81, 152-167. [CrossRef]

16. Šesták, P.; Černý, M.; He, J.Y.; Zhang, Z.L.; Pokluda, J. Multiaxial stress-strain response and displacive transformations in NiTi alloy from first principles. Acta Mater. 2016, 109, 223-229. [CrossRef]

17. Laplanche, G.; Birk, T.; Schneider, S.; Frenzel, J.; Eggeler, G. Effect of temperature and texture on the reorientation of martensite variants in NiTi shape memory alloys. Acta Mater. 2017, 127, 143-152. [CrossRef]

18. Xiao, Y.; Zeng, P.; Lei, L.P.; Zhang, Y.Z. In situ observation on temperature dependence of martensitic transformation and plastic deformation in superelastic NiTi shape memory alloy. Mater. Des. 2017, 134, 111-120. [CrossRef]

19. Haskins, J.B.; Lawson, J.W. Finite temperature properties of NiTi from first principles simulations: Structure, mechanics, and thermodynamics. J. Appl. Phys. 2017, 121, 205103. [CrossRef]

20. Lee, J.; Ikeda, Y.; Tanaka, I. Solution effect on improved structural compatibility of NiTi-based alloys by systematic first-principles calculations. J. Appl. Phys. 2019, 125, 055106. [CrossRef]

21. Liu, G.T.; Liu, H.Y.; Feng, X.L.; Redfern, S.A.T. High-pressure phase transitions of nitinol NiTi to a semiconductor with an unusual topological structure. Phys. Rev. B 2018, 97, 140104. [CrossRef]

22. Ataei, M.; Zarei-Hanzaki, A.; Shamsolhodaei, A. Shape memory response and mechanical properties of warm deformed NiTi intermetallic alloy. Mater. Sci. Eng. A 2017, 680, 291-296. [CrossRef]

23. Wang, L.; Ma, L.; Liu, C.; Zhong, Z.Y.; Luo, S.N. Texture-induced anisotropic phase transformation in a NiTi shape memory alloy. Mater. Sci. Eng. A 2018, 718, 96-103. [CrossRef]

24. Zeng, Z.Y.; Hu, C.E.; Cai, L.C.; Chen, X.R.; Jing, F.Q. First-principles determination of the structure, elastic constant, phase diagram and thermodynamics of NiTi alloy. Phys. B 2010, 405, 3665-3672. [CrossRef]

25. Sandoval, L.; Haskins, J.B.; Lawson, J.W. Stability, structure, and suppression of the martensitic transition temperature by B19' compound twins in NiTi: Ab initio and classical simulations. Acta Mater. 2018, 154, 182-189. [CrossRef]

26. Milman, V.; Winkler, B.; White, J.A.; Pickard, C.J.; Payne, M.C.; Akhmatskaya, E.V.; Nobes, R.H. Electronic Structure, Properties, and Phase Stability of Inorganic Crystals: A Pseudopotential Plane-Wave Study. Int. J. Quantum Chem. 2000, 77, 895-910. [CrossRef]

27. Segall, M.D.; Lindan, P.J.D.; Probert, M.J.; Pickard, C.J.; Hasnip, P.J.; Clark, S.J.; Payne, M.C. First-Principles Simulation: Ideas, Illustrations and the CASTEP Code. J. Phys. Condens. Matter 2002, 14, 2717-2744. [CrossRef]

28. Clark, S.J.; Segall, M.D.; Pickard, C.J.; Hasnip, P.J.; Probert, M.I.J.; Refson, K.; Payne, M.C. First principles methods using CASTEP. Z. Krist. Cryst. Mater. 2005, 220, 567-570. [CrossRef]

29. Perdew, J.P.; Burke, K.; Ernzerhof, M. Generalized Gradient Approximation Made Simple. Phys. Rev. Lett. 1996, 77, 3865-3868. [CrossRef]

30. Vanderbilt, D. Soft self-consistent pseudopotentials in a generalized eigenvalue formalism. Phys. Rev. B 1990, 41, 7892-7895. [CrossRef]

31. Monkhorst, H.J.; Pack, J.D. Special points for Brillouin-zone integrations. Phys. Rev. B 1976, 13, 5188-5192. [CrossRef]

32. Fischer, T.H.; Almlof, J. General methods for geometry and wave function optimization. J. Phys. Chem. 1992, 96, 9768-9774. [CrossRef]

33. Birch, F. Finite Elastic Strain of Cubic Crystals. Phys. Rev. 1947, 71, 809-824. [CrossRef]

34. Cheng, D.Y.; Zhao, S.J.; Wang, S.Q.; Ye, H.Q. First-principles study of the elastic properties and electronic structure of NiTi, CoTi and FeTi. Philos. Mag. A 2001, 81, 1625-1632. [CrossRef]

35. Hatcher, N.; Kontsevoi, O.Y.; Freeman, A.J. Role of elastic and shear stabilities in the martensitic transformation path of NiTi. Phys. Rev. B 2009, 80, 144203. [CrossRef] 
36. Kadkhodaei, S.; Walle, A.V.D. First-principles calculations of thermal properties of the mechanically unstable phases of the PtTi and NiTi shape memory alloys. Acta Mater. 2018, 147, 296-303. [CrossRef]

37. Mizuno, M.; Araki, H.; Shirai, Y. Compositional dependence of structures of NiTi martensite from first principles. Acta Mater. 2015, 95, 184-191. [CrossRef]

38. Chen, L.; Li, Y.F.; Xiao, B.; Zheng, Q.L.; Gao, Y.M.; Zhao, S.Y.; Wang, Z.C. First-principles calculation on the adhesion strength, fracture mechanism, interfacial bonding of the NiTi (111)// $\alpha-\mathrm{Al} 2 \mathrm{O} 3$ (0001) interfaces. Mater. Des. 2019, 183, 108119. [CrossRef]

39. Sittner, P.; Lukás, P.; Neov, D.; Novák, V.; Toebbens, D.M. In situ neutron diffraction studies of martensitic transformations in NiTi. J. Phys. IV 2003, 112, 709-712. [CrossRef]

40. Wang, J.H.; Yip, S.; Phillpot, S.R.; Wolf, D. Crystal instabilities at finite strain. Phys. Rev. Lett. 1993, 71, 4182-4185. [CrossRef]

41. Patil, S.K.R.; Khare, S.V.; Tuttle, B.R.; Bording, J.K.; Kodambaka, S. Mechanical stability of possible structures of PtN investigated using first-principles calculations. Phys. Rev. B 2006, 73, 104118. [CrossRef]

42. Hu, Q.M.; Yang, R.; Lu, J.M.; Wang, L.; Johansson, B.; Vitos, L. Effect of Zr on the properties of (TiZr)Ni alloys from first-principles calculations. Phys. Rev. B 2007, 76, 224201. [CrossRef]

43. Wagner, M.F.X.; Windl, W. Lattice stability, elastic constants and macroscopic moduli of NiTi martensites from first principles. Acta Mater. 2008, 56, 6232-6245. [CrossRef]

44. Mercier, O.; Melton, K.N.; Gremaud, G.; Hägi, J. Single-crystal elastic constants of the equiatomic NiTi alloy near the martensitic transformation. J. Appl. Phys. 1980, 51, 1833-1834. [CrossRef]

45. Bakhtiari, S.R.; Liu, J.Z.; Shariat, B.S.; Yang, H.; Liu, Y.N. Role of hydrostatic pressure on the phase stability, the ground state, and the transformation pathways of NiTi alloy. Scr. Mater. 2018, 151, 57-60. [CrossRef]

46. Pugh, S.F. XCII. Relations between the elastic moduli and the plastic properties of polycrystalline pure metals. Philos. Mag. 1954, 45, 823-843. [CrossRef]

47. Cao, Y.; Zhu, J.C.; Nong, Z.S.; Yang, X.W.; Liu, Y.; Lai, Z.H. First-principles studies of the structural, elastic, electronic and thermal properties of Ni3Nb. Comput. Mater. Sci. 2013, 77, 208-213. [CrossRef]

48. Iotova, D.; Kioussis, N.; Lim, S.P. Electronic structure and elastic properties of the Ni3X (X= Mn, Al, Ga, Si, Ge) intermetallics. Phys. Rev. B 1996, 54, 14413-14422. [CrossRef] [PubMed]

49. Hill, R. The elastic behaviour of a crystalline aggregate. Proc. Phys. Soc. A 1952, 65, 349-354. [CrossRef]

50. Mattesini, M.; Ahuja, R.; Johansson, B. Cubic Hf3N4 and Zr3N4: A class of hard materials. Phys. Rev. B 2003, 68, 184108. [CrossRef]

51. Fu, H.Z.; Li, D.H.; Peng, F.; Gao, T.; Cheng, X.L. Ab initio calculations of elastic constants and thermodynamic properties of NiAl under high pressures. Comput. Mater. Sci. 2008, 44, 774-778. [CrossRef]

52. Yoo, M.H. On the theory of anomalous yield behavior of Ni3Al-Effect of elastic anisotropy. Scr. Metall. 1986, 20, 915-920. [CrossRef]

53. Lau, K.; Mccurdy, A.K. Elastic anisotropy factors for orthorhombic, tetragonal, and hexagonal crystals. Phys. Rev. B 1998, 58, 8980-8984. [CrossRef]

54. Fu, H.Z.; Li, X.F.; Liu, W.F.; Ma, Y.M.; Gao, T.; Hong, X.H. Electronic and dynamical properties of NiAl studied from first principles. Intermetallics 2011, 19, 1959-1967. [CrossRef]

55. Reed, R.P.; Clark, A.F. American Society of Metals; Metals Park: Geauga County, OH, USA, 1983.

56. Friák, M.; Šob, M.; Vitek, V. Ab initio calculation of tensile strength in iron. Philos. Mag. 2003, 83, 3529-3537. [CrossRef]

57. Fu, H.Z.; Peng, W.M.; Gao, T. Structural and elastic properties of ZrC under high pressure. Mater. Chem. Phys. 2009, 115, 789-794. [CrossRef]

58. Pettifor, D.G. Theoretical predictions of structure and related properties of intermetallics. Mater. Sci. Technol. 1992, 8, 345-349. [CrossRef]

59. Johnson, R.A. Analytic nearest-neighbor model for FCC metals. Phys. Rev. B 1988, 37, 3924-3931. [CrossRef] [PubMed]

(C) 2019 by the authors. Licensee MDPI, Basel, Switzerland. This article is an open access article distributed under the terms and conditions of the Creative Commons Attribution (CC BY) license (http://creativecommons.org/licenses/by/4.0/). 